\title{
MiRNAs Associated Polymorphisms in the 3'UTR of MET Promote the Risk of Non- Small Cell Lung Cancer
}

\author{
Xiaojue Zhu ${ }^{\mathrm{a}}$ Changqing Fu ${ }^{\mathrm{b}}$ Lihua Zhang ${ }^{\mathrm{a}}$ Guoxing $\mathrm{Xu}^{\mathrm{a}}$ Shusheng Wang ${ }^{\mathrm{a}}$
}

${ }^{a}$ Clinical laboratory, Zhangjiagang First People's Hospital, Suzhou, ${ }^{\mathrm{b}} \mathrm{Clinical}$ laboratory, Zhangjiagang Leyu Hospital, Suzhou, China

\author{
Key Words \\ SNP • MET • Non-small lung cancer $\bullet$ MiRNA
}

\begin{abstract}
Background/Aims: MET can act as an oncogene and its signaling server has essential roles in regulating tumorigenesis. Polymorphisms in MET have been reported to be associated with poor prognosis in human cancer, but an association with the risk of human non-small-cell lung cancer (NSCLC) has not been found so far. In this study rs41281081 and rs76322625, located in the 3'UTR of MET, were selected to evaluate their relationship with the risk of NSCLC among the Chinese population. Methods: A questionnaire, SNaPshot genotype assay, real time PCR assay, cell transfection and the dual luciferase reporter assay were used. Single-nucleotide polymorphisms (SNPs) of rs41281081 and rs76322625 in the 3' untranslated region (UTR) of MET was involved as a risk factor in the occurrence of NSCLC. Results: SNP rs41281081 could be regulated by miR-335 and rs76322625 could be regulated by miR-1026 to cause an up-regulation of MET in patients with NSCLC. Furthermore, the carriers of the GA and AA genotypes in rs41281081, and the CU and UU genotypes in rs76322625 presented with poor cell differentiation and large tumor size, as well as a high probability of metastasis. Conclusion: Our findings have shown that the SNPs rs41281081 and rs76322625 in MET 3'UTR, through disruption of the regulatory role of miR-335 and miR-1026 in MET expression, may act as promoting factors in the pathogenesis of NSCLC.
\end{abstract}

Copyright @ 2015 S. Karger AG, Basel

\section{Introduction}

Non-small-cell lung carcinoma (NSCLC) is any type of epithelial lung cancer other than small-cell lung carcinoma (SCLC). It accounts for approximately $85 \%$ of all lung cancers [1-3]. Histologically, NSCLC is divided into adenocarcinoma and squamous cell carcinoma (SCC). Smoking is the major causes of NSCLC (78\% in men and $90 \%$ in women); besides smoking, other causes of NSCLC including asbestos exposure, radon exposure, halogen ether Xi. Zhu and C. Fu contributed equally to this work.

Dr. Wang Shusheng

KARGER 125
Clinical laboratory, Zhangjiagang First People's Hospital,

West Jiyang Road 68\#, Suzhou, (China)

E-Mail wangss1089@163.com 
exposure and chronic interstitial pneumonitis $[4,5]$. Traditional treatment for NSCLC is not sufficient, given the increasing number of people suffering with NSCLC [6-9]. Improving results with the candidate gene approach have led to its growing acceptance as a potentially useful method for investigating genetic risk factors for NSCLC among Chinese people.

MET (MET proto-oncogene, receptor tyrosine kinase), also called c-Met and hepatocyte growth factor receptor (HGFR), is a protein that in humans is encoded by the MET gene. MET is a membrane receptor that is essential for embryonic development and wound healing. It is normally expressed by cells of epithelial origin, while expression of HGF is restricted to cells of mesenchymal origin. Upon HGF stimulation, MET induces several biological responses that collectively give rise to a program known as invasive growth. Abnormal MET activation has been found in several cancers, including liver cancer, gastric cancer and colon cancer, as well as leukemia. Expression of MET can serve as a ideal indicator of poor prognosis of NSCLC. Prolonged or continuous activity of the receptor leads to excessive cell proliferation and is related to the development or progression of neoplastic disease. C-MET inhibitors can be classified into three groups: small-molecule tyrosine kinase inhibitors of the c-MET receptor (crizotinib, tivantinib, cabozantinib, foretinib), as well as monoclonal antibodies against c-MET (onartuzumab) and against the HGF ligand (ficlatuzumab, rilotumumab). The efficacy and safety of these agents is assessed both in monotherapy and in combination with other molecularly targeted agents [10-12]. F Furthermore, the toxicity profile of c-MET inhibitors is completely different from that of standard chemotherapy [13]. Aberrantly active MET can trigger tumor growth, angiogenesis and metastasis. In addition to mutation and abnormal activation of its upstream, overexpression of MET has also been reported to be associated with miRNA [14-16].

MiRNAs are small, non-coding RNA molecules of 19-25 nucleotides which have been reported to play important roles by regulating cell differentiation, proliferation, migration and apoptosis [17-20]. MiRNAs not only negatively regulate expression of their target genes at the posttranscription level, through binding to 3' untranslated regions (UTRs) of their targets' messenger RNAs [21, 22], but they also regulate the 3'UTR region, which harbors single-nucleotide polymorphisms (SNPs). Increasing numbers of studies have provided evidence that SNPs located in the miRNA (miRSNPs) binding sites affect the binding of miRNAs with the target genes, resulting in the reduction or increase in target mRNA translation, and thus are associated with the susceptibility to cancers[23-25].

In this study, we focused on the SNPs in the 3'UTR of MET, which have rarely been reported before. By using bioinformatics software (http://www.bioguo.org/miRNASNP/), we obtained all the SNPs which could be regulated by different miRNAs as candidate SNPs, and further investigated the allele distribution in a case-control study.

\section{Materials and Methods}

Study subjects

The hospital-based case-control study consists of 873 patients newly diagnosed with NSCLC and 711 cancer-free controls. All the subjects were genetically unrelated Han Chinese recruited from the first people's hospital of Zhangjiagang City (Zhangjiagang China), January 2010 and September 2014. Patients with other hematological disorders, previous history of cancers, radiotherapy and chemotherapy were excluded. The cancer-free control subjects from the same geographic area showed no evidence of genetic relationship with the cases. The patients were classified according to World Health Organization classification. This study was approved by the Ethical Committee of the first people's hospital of Zhangjiagang City, and every patient had written informed consent.

\section{Genotype}

We extracted genomic DNA from peripheral whole blood of every validation subject by using QIAamp DNA blood mini kits (Qiagen, Germany) according to the manufacturer's instructions. Genotyping was performed with the TaqMan SNP Genotyping Assay. The PCR reactions were carried out in a total volume of 


\section{Cellular Physiology Cell Physiol Biochem 2015;37:1159-1167 \begin{tabular}{ll|l} 
and Biochemistry 1159/000430239 & $\begin{array}{l}\text { O 2015 S. Karger AG, Basel } \\
\text { www.karger.com/cpb }\end{array}$ \\
\hline
\end{tabular} \\ Zhu et al.: MiRNA Associated SNPs in NSCLC}

$5 \mu \mathrm{L}$ containing TaqMan Universal Master Mix, 80X SNP Genotyping AssayMix, Dnase-free water and 10-ng genomic DNA. The PCR conditions were $2 \mathrm{~min}$ at $50^{\circ} \mathrm{C}, 10 \mathrm{~min}$ at $95^{\circ} \mathrm{C}$, followed by 40 cycles at $95^{\circ} \mathrm{C}$ for 15 sec and $60^{\circ} \mathrm{C}$ for $1 \mathrm{~min}$. The 384-well ABI 7900HT Real Time PCR System.

\section{Real time PCR assay}

Real time polymerase chain reaction (RT-PCR) was performed to determine whether the $\mathrm{C}$ to $\mathrm{T}$ mutation changed the expression level of MET. The amplification conditions were $95^{\circ} \mathrm{C}$ for 10 minutes, followed by 40 cycles of $95^{\circ} \mathrm{C}$ for 30 seconds, $55^{\circ} \mathrm{C}$ for 40 seconds, and $72^{\circ} \mathrm{C}$ for 30 seconds, and finally $4^{\circ} \mathrm{C}$ for 30 minutes for cooling.

\section{Cell lines and cell culture}

NSCLC cell lines and A549 and NCIH1975 were purchased from the Chinese Academy of Sciences Cell Bank. All cells were cultured in RPMI-1640 (Gibco, USA) supplemented with 10\% fetal bovine serum (Invitrogen, Carlsbad, USA) and grown in humidified 5\% CO2 at 37 ${ }^{\circ} \mathrm{C}$. MiR-355 and miR-1026 mimics and normal control were obtained from Genepharma (Shanghai, China).The transfection was conducted by using Lipofectamine 2000 (Invitrogen Corp, CA, USA).

Prediction of miRNAs binding to the SNP

Based on our bioinformatics analysis by using the bioinformatics software (http://www.bioguo.org/ miRNASNP/) to predict the related SNPs in the 3'UTR of MET which could regulated by different miRNAs.

Construction of luciferase-based reporter plasmids

All the fragment of the 3'UTR containing the mutated alleles we desired were amplified and constructed. The PCR production was cloned into the pGL3-promoterless luciferase-based plasmid (Promega, WI, USA) at the cloning site between KpnI and XhoI. The amplified fragment was verified by DNA sequencing.

\section{Dual-luciferase reporter assay}

The 3'-UTR sequence of MET predicted to interact with miR-603 or a mutated sequence with the predicted target sites were inserted into the KpnI and XhoI sites of pGL3 promoter vector (Genscript, Nanjing, China). For reporter assay, cells were plated onto 24-well plates and transfected with $100 \mathrm{ng}$ of pGL3-MET wild, pGL3-MET mutant, miRNA and their mimics, respectively by using Lipofectamine 2000 (Invitrogen Corp, CA, USA). A Renilla luciferase vector pRL-SV40 (5 ng) was also co-transfected to normalize the differences in transfection efficiency. Transfection was repeated three times in triplicate

\section{Statistical analysis}

The association between rs41281081 and rs76322625 genotypes and the risk of NSCLC was evaluated by calculating the odds ratios (ORs) and their 95\% confidence intervals (CIs) using univariate and multivariate logistic regression analysis. Stratification analysis was performed according to the clinical characteristic and risk classification to determine the genotype distribution in cases and controls as well as their association with the risk of NSCLC. The difference of the expression levels of MET with three genotypes and the difference of the relative luciferase activities between the wild and mutant genotype were evaluated by independent-sample $t$ test. All statistical tests were two-sided and $\mathrm{P}<0.05$ was considered statistically significant. Statistical analysis was performed with SPSS 13.0 (SPSS Ltd.) and SAS software (version 9.1.3; SAS Institute, Cary, NC, USA). The graphs were generated by Graphpad Prism 5.0 (Graphpad Software, Inc.).

\section{Results}

\section{Participant characteristics}

The characteristics of the 873 patients with NSCLC and 711 healthy controls are summarized in Table 1 . No statistically significant differences were observed between cases and controls in terms of sex and age (both $\mathrm{P}>0.05$ ). This indicates that the frequency matching was adequate. Patients suffering from exposure to smoking were indicated to be the susceptible population by comparison with controls (Table 1). 
Table 1. Frequency distributions of selected variables in patients and cancer-free controls. *Two-sided chi-square test for either genotype distributions or allele frequencies between cases and controls
Table 2. Association between SNPs and NSCLC. Chr = chromosome; UTR = Untranslated Regions
Table 3. Genotype frequencies of the MET rs41281081 and rs76322625 polymorphism among NSCLC cases and controls. aThe ORs, 95\% CIs and $P$ value were calculated after adjusting for age, gender, parental smoking, drinking and family caner history

\begin{tabular}{|c|c|c|c|c|c|}
\hline \multirow[t]{2}{*}{ Variables } & \multicolumn{2}{|c|}{ Cases $(n=873)$} & \multicolumn{2}{|c|}{ Controls $(n=711)$} & \multirow[t]{2}{*}{$P^{*}$} \\
\hline & $N$ & $\%$ & $N$ & $\%$ & \\
\hline Age (years) & & & & & 0.0314 \\
\hline$\leq 50$ & 413 & 47.31 & 375 & 52.74 & \\
\hline$>50$ & 460 & 52.69 & 336 & 47.26 & \\
\hline Gender & & & & & 0.527 \\
\hline Male & 433 & 49.59 & 364 & 51.20 & \\
\hline Female & 440 & 50.41 & 347 & 48.80 & \\
\hline Parental smoking status & & & & & $<0.0001$ \\
\hline Negative & 318 & 36.43 & 353 & 49.65 & \\
\hline Positive & 555 & 63.57 & 358 & 50.35 & \\
\hline \multicolumn{6}{|l|}{ Differentiation grade } \\
\hline Well & 318 & 36.43 & & & \\
\hline Moderate & 253 & 28.98 & & & \\
\hline Poorly & 302 & 34.59 & & & \\
\hline \multicolumn{6}{|l|}{ Tumor Size $(\mathrm{cm})$} \\
\hline$\leq 3 \mathrm{~cm}$ & 416 & 47.65 & & & \\
\hline$>3 \mathrm{~cm}$ & 457 & 52.35 & & & \\
\hline \multicolumn{6}{|l|}{ Metastasis } \\
\hline Yes & 489 & 56.01 & & & \\
\hline No & 384 & 43.99 & & & \\
\hline
\end{tabular}

\begin{tabular}{ccccc}
\hline SNP & chr & $\begin{array}{c}\text { 3'UTR } \\
\text { position }\end{array}$ & $\begin{array}{c}\text { Associated } \\
\text { miRNA }\end{array}$ & Allele \\
\hline rs59399612 & 7 & $212-234$ & miR-122 & U/G \\
rs41281081 & 7 & $68-94$ & miR-335 & G/A \\
rs75361918 & 7 & $1369-1391$ & miR-767-3p & $\mathrm{C} / \mathrm{G}$ \\
rs1129355 & 7 & $182-203$ & miR-1204 & $\mathrm{C} / \mathrm{G}$ \\
rs76322625 & 7 & $1968-1988$ & $\mathrm{miR}-1026$ & $\mathrm{C} / \mathrm{U}$ \\
rs59399612 & 7 & $214-233$ & $\mathrm{miR}-3659$ & $\mathrm{U} / \mathrm{G}$ \\
\hline
\end{tabular}

\begin{tabular}{cccccccc}
\hline Genotype & \multicolumn{10}{c}{ Cases $(n=873)$} & \multicolumn{2}{c}{ Controls $(n=711)$} & OR & $P$ Value $^{\mathrm{a}}$ \\
& $N$ & $\%$ & $N$ & $\%$ & $(95 \% \mathrm{CI})$ a & \\
\hline GG & 275 & 31.50 & 419 & 58.93 & 1.00 & $<0.0001$ \\
GA & 326 & 37.34 & 195 & 27.43 & $2.54(1.34-1.93)$ & \\
AA & 272 & 31.16 & 97 & 11.11 & $2.73(1.27-1.79)$ & \\
A Carrier & 598 & 68.50 & 292 & 38.54 & $3.12(1.55-1.98)$ & $<0.0001$ \\
& & \multicolumn{7}{c}{ rs41281081 } \\
CC & 378 & 43.30 & 518 & 72.86 & 1.00 & $<0.0001$ \\
CU & 347 & 39.75 & 143 & 20.11 & $3.32(1.45-1.79)$ & \\
UU & 148 & 16.95 & 50 & 5.73 & $4.05(1.36-1.79)$ & \\
U Carrier & 495 & 56.70 & 193 & 25.84 & $3.51(1.05-1.85)$ & $<0.0001$ \\
\hline
\end{tabular}

The miRSNPs in the MET gene 3'UTR

In order to investigate the miRNA-associated SNPs in the 3'UTR of MET, we first searched the SNP databases NCBI db SNP BUILED 129 and ENSEMBL v58 to find all the SNPs in the 3'UTR of the MET gene with the minor allele frequency (MAF) $>0.05$. We then used bioinformatics software (Diana-Micro, RNAhybrid) to predict miRNAs that can bind to the MET 3'UTR. The miRNASNP database was also applied to explore the miRNAs which could also bind to the 3'UTR of patients harboring the SNP, as shown in Table 2. Finally, we obtained six SNPs in the 3'UTR which could be regulated by three different miRNAs (miR- 


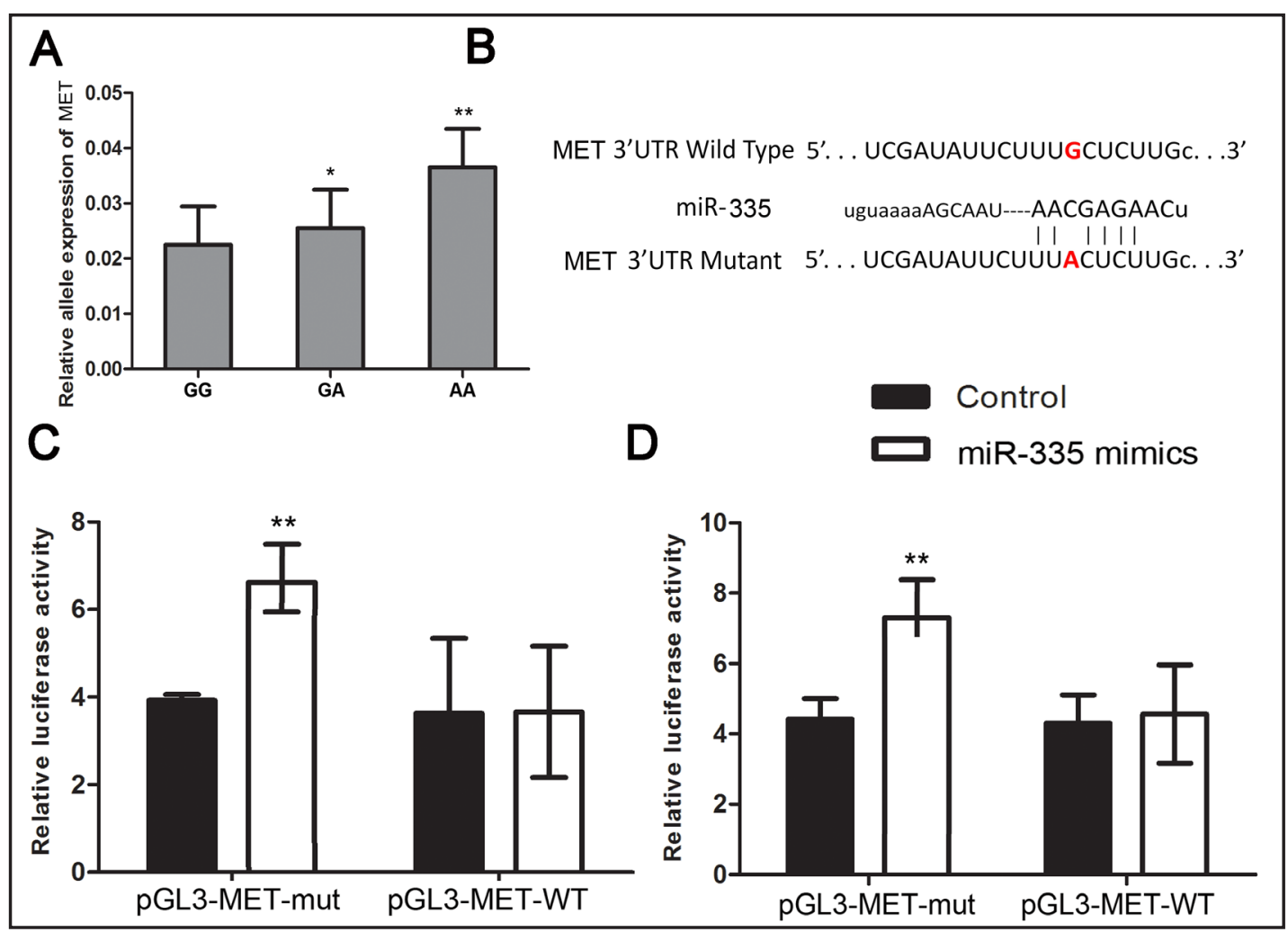

Fig. 1. SNP rs41281081 in 3'UTR of NSCLC patients with GA/AA genotype can up-regulate of MET transcription by deregulated by miR-335. (A) The expression level of MET was determined by RT-PCR in patients with GG, GA and AA genotypes. (B) Bioinformatics predicted the binding site between the miR-335 with MET and the mutation types were conducted into the pGL3 plasmid as presented. (C) Cells were co-transfected with miR-335 mimics or control, Renilla luciferase vector pRL-SV40 for $48 \mathrm{~h}$. Both firefly and Renilla luciferase activities were measured in the same sample. Firefly luciferase signals were normalized with Renilla luciferase signals. Left panel indicated the A549 cell line while the right indicated NCIH1975 cell lines. Data was presented as the mean \pm SEM. * indicates a significant difference $(P<0.05)$.

122, miR-335, miR-767-3p, miR-1024, miR-1026 and miR-3659). The positions of the SNPs in the 3'UTR of MET as well as the variants were listed. Further genotyping was performed to detect the distribution of the alleles of the six SNPs in our research.

\section{Correlation of rs 76322625 and rs41281081 with NSCLC}

Interestingly, two SNPs (rs76322625 and rs41281081) showed a significant difference between NSCLC patients and controls, as listed in Table 3. The results showed that the genotypes of both rs41281081 and rs76322625 were in a Hardy-Weinberg equilibrium distribution pattern in the healthy control group $(\mathrm{P}<0.0001)$. Further, logistic regression analysis revealed that the NSCLC genotype GG in SNP rs41281081 presented a significantly decreased risk of NSCLC when compared with the A carrier genotypes (GA and AA; $\mathrm{P}<0.0001$ ). Similarly, rs76322625 presented a significantly decreased risk of NSCLC when compared with the U carrier genotype (CU and UU; P < 0.0001). Logistic regression analyses indicated that the rs41281081 GA and AA genotypes were significantly associated with NSCLC risk $(\mathrm{OR}=2.54,95 \% \mathrm{CI}=1.34-1.93$ for $\mathrm{GA} ; \mathrm{OR}=2.73,95 \% \mathrm{CI}=1.27-1.79$ for $\mathrm{AA}$; and $\mathrm{OR}=3.12$; $95 \% \mathrm{CI}=1.55-1.98$ for A carriers). Similarly, the rs76322625 CU and UU genotypes were also significantly associated with NSCLC risk (OR $=3.32,95 \% \mathrm{CI}=1.45-1.79$ for $\mathrm{CU}$; OR = $4.05,95 \% \mathrm{CI}=1.36-1.79$ for $\mathrm{UU}$; and $\mathrm{OR}=3.51 ; 95 \% \mathrm{CI}=1.05-1.85$ for U carriers). All ORs were adjusted for sex, age, and smoking status, drinking history and family cancer history. 


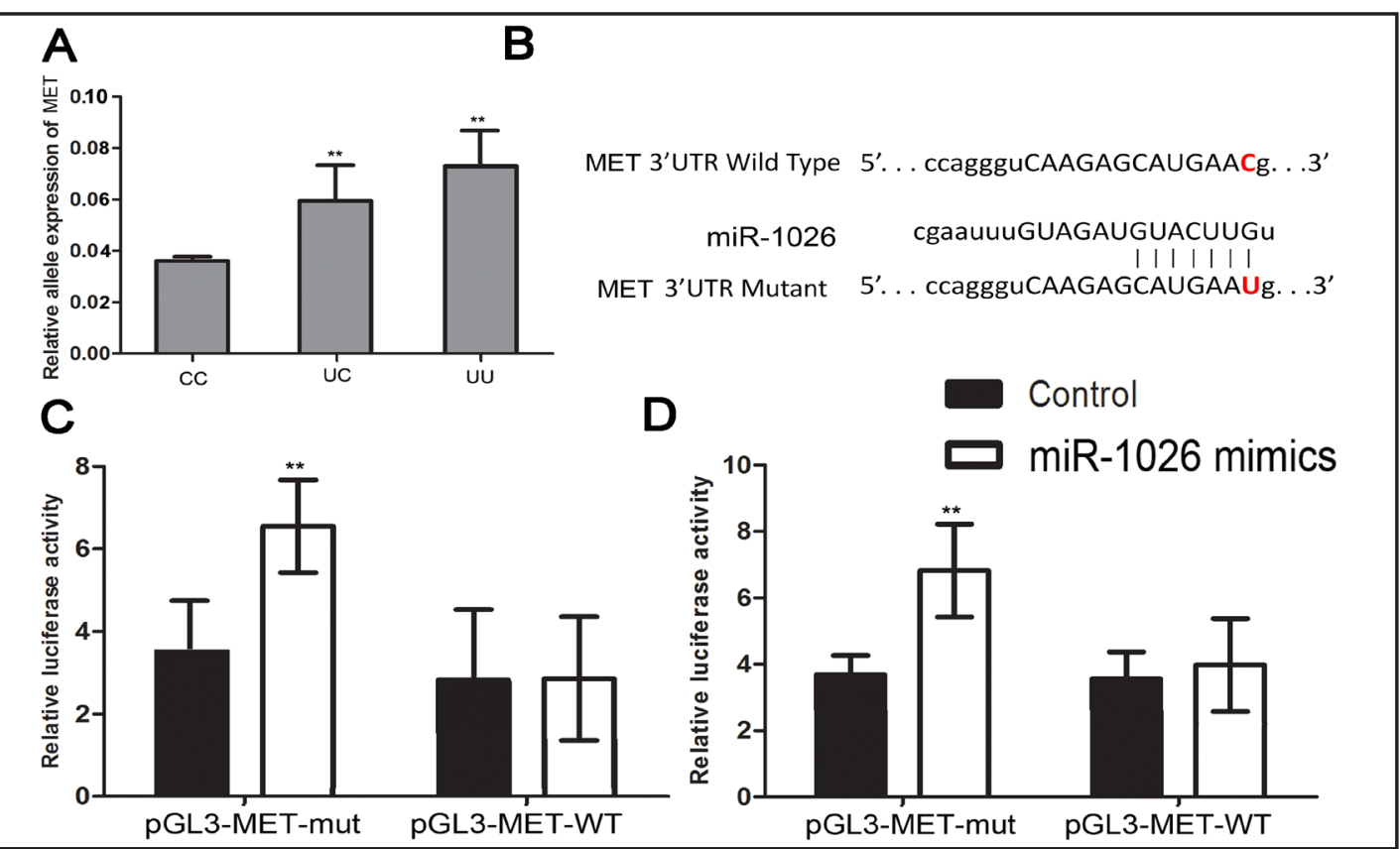

Fig. 2. SNP rs76322625 in 3'UTR of NSCLC patients with CU/UU genotype can up-regulate of MET transcription by deregulated by miR-1026. (A) The expression level of MET was determined by RT-PCR in patients with CC, CU and UU genotypes. (B) Bioinformatics predicted the binding site between the miR-1026 with MET and the mutation types were conducted into the pGL3 plasmid as presented. (C) Cells were co-transfected with miR-1026 mimics or control, Renilla luciferase vector pRL-SV40 for $48 \mathrm{~h}$. Both firefly and Renilla luciferase activities were measured in the same sample. Firefly luciferase signals were normalized with Renilla luciferase signals. Left panel indicated the A549 cell line while the right indicated NCIH1975 cell lines. Data was presented as the mean \pm SEM. * indicates a significant difference $(P<0.05)$.

The effect of rs76322625 and rs41281081 on the regulatory role of miRNAs in MET expression

The SNPs rs41281081 and rs76322625 were predicted to be located in the binding sites of miR-335 and miR-1026, respectively. We hypothesized that the expression of MET might be regulated by these miRNAs, and could be affected by rs41281081 and rs76322625. To determine whether or not the inhibitory role of these miRNAs was impacted by the two SNPs, we first measured the level of expression of MET in patients harboring the GG, GA and AA genotypes, as well as the patients with CC, CU and UU genotypes. We found that patients with GA or AA genotypes presented a significantly higher level of MET in comparison with the patients with the GG genotype. Similarly, for rs76322625 of MET 3'UTR, the patients with genotype CC or CU also had a significantly greater level of MET than those with the UU genotype (Fig. 1A and 2A). We constructed pGL3 vectors including the allele-specific binding sequences (Fig. 1B and 2B), and then used them to co-transfect, with miR-335 and miR-1026 as well as controls, the NSCLC cell lines A549 and NCIH1975. As presented in Fig. 1 (C and D) and Fig. 2 (C and D), we found that the expression of both A-allele-specific and U-allele-specific pGL3 constructs was not significantly suppressed by miR-335 or miR1026 on rs76322625 and rs41281081 (Fig. 1 (C and D) and Fig. 2 (C and D)). These findings suggest that rs76322625 and rs41281081 are regulated by miR-335 or miR-1026.

\section{Stratified analyses of the association between MET polymorphism and NSCLC risk}

Stratified analysis was used to investigate the association of the rs76322625 and rs41281081 genotypes with the clinicopathological parameters of NSCLC (Table 4 and 5). We found a significant association of the rs76322625 and rs41281081 genotypes with tumor size, differentiation and metastasis. Comparing with GG and CC homozygotes, the carriers of 
Table 4. Stratified analysis of rs41281081 genotype with clinicopathological parameters of NSCLC. *Two-sided chi-square test for either genotype distributions or allele frequencies between cases and controls

\begin{tabular}{|c|c|c|c|c|c|}
\hline Feather & GG & GA & $\mathrm{AA}$ & $\begin{array}{l}\text { GG vs GA } \\
P \text { Value* }\end{array}$ & $\begin{array}{l}\text { GG vs AA } \\
P \text { Value* }\end{array}$ \\
\hline \multicolumn{6}{|l|}{ Age (years) } \\
\hline$\leq 50$ & 243 & 105 & 65 & 0.108 & 0.402 \\
\hline$>50$ & 246 & 137 & 77 & & \\
\hline \multicolumn{6}{|l|}{ Gender } \\
\hline Male & 231 & 125 & 77 & 0.261 & 0.143 \\
\hline $\begin{array}{l}\text { Female } \\
\text { Differentiation grade }\end{array}$ & 258 & 117 & 65 & & \\
\hline Well & 175 & 125 & 18 & $<0.0001$ & $<0.0001$ \\
\hline Moderate & 147 & 48 & 58 & & \\
\hline Poorly & 167 & 69 & 66 & & \\
\hline \multicolumn{6}{|l|}{ Tumor Size(cm) } \\
\hline$\leq 3 \mathrm{~cm}$ & 176 & 118 & 122 & 0.0009 & $<0.0001$ \\
\hline$>3 \mathrm{~cm}$ & 313 & 124 & 20 & & \\
\hline \multicolumn{6}{|l|}{ Metastasis } \\
\hline Yes & 208 & 163 & 118 & $<0.0001$ & $<0.0001$ \\
\hline No & 281 & 79 & 24 & & \\
\hline Feather & $\mathrm{UU}$ & $\mathrm{UC}$ & $\mathrm{CC}$ & $\begin{array}{l}\text { UU vs UC } \\
P \text { Value* }\end{array}$ & $\begin{array}{l}\text { UU vs CC } \\
P \text { Value* }\end{array}$ \\
\hline \multicolumn{6}{|l|}{ Age (years) } \\
\hline$\leq 50$ & 174 & 166 & 73 & 0.63 & 0.50 \\
\hline$>50$ & 204 & 181 & 75 & & \\
\hline \multicolumn{6}{|l|}{ Gender } \\
\hline Male & 185 & 185 & 84 & 0.24 & 0.11 \\
\hline $\begin{array}{l}\text { Female } \\
\text { Differentiation grade }\end{array}$ & 193 & 162 & 64 & & \\
\hline Well & 201 & 139 & 35 & 0.0012 & $<0.0001$ \\
\hline Moderate & 101 & 108 & 56 & & \\
\hline $\begin{array}{l}\text { Poorly } \\
\text { Tumor Size(cm) }\end{array}$ & 76 & 100 & 57 & & \\
\hline$\leq 3 \mathrm{~cm}$ & 231 & 139 & 119 & $<0.0001$ & $<0.0001$ \\
\hline $\begin{array}{l}>3 \mathrm{~cm} \\
\text { Tumor Number }\end{array}$ & 147 & 208 & 29 & & \\
\hline Solitary & 201 & 149 & 139 & 0.0059 & $<0.0001$ \\
\hline Multiple & 177 & 198 & 9 & & \\
\hline Metastasis & & & & & \\
\hline Yes & 216 & 163 & 110 & 0.0062 & 0.0003 \\
\hline No & 162 & 184 & 38 & & \\
\hline
\end{tabular}

the A or U genotype presented significantly larger tumors, poorer cellular differentiation and a high potential for metastasis.

\section{Discussion}

In this study, we investigated the relationship between miRSNPs within the 3'UTR of the MET gene and the risk of NSCLC. We observed that MET rs76322625 and rs41281081 with the GA, AA or CU, UU genotypes were associated with significantly increased tumor size, poor cell differentiation and metastasis of NSCLC. We further found that the SNPs rs76322625 and rs41281081, located in the binding sites of miR-1026 and miR-335, can disrupt their inhibitory role on MET expression, and play an important role in the development of NSCLC. 
Several studies have reported increased expression of MET in human NSCLC. For example, overexpression of c-MET is frequently detected in adenocarcinoma cells, whereas upregulated HGF was detected in alveolar type II (ATII) cells. Overexpression of HGF has been correlated with cigarette smoking and tumor stages. An in vitro study showed that nicotine can activate HGF expression in ATII cells and lung cancer cells, which imply that HGF/c-MET signaling can be abnormally activated by environmental stimuli [26]. In addition, Xu et al. indicated that c-MET can be up-regulated in the response to hypoxia. EGFR signaling can regulate MET levels through HIF-1alpha, and MET is a key downstream mediator of EGFRinduced invasiveness in EGFR-dependent NSCLC cells [27]. However, little research has been carried out on the SNP of MET and its influence on tumorigenesis.

Furthermore, c-MET can be regulated by miRNA. For example, MiR-335 was found to negatively regulate the c-MET protein level by directly targeting its 3'UTR. Forced expression of miR-335 decreased c-MET expression at the protein level and consequently diminished hepatocyte growth factor (HGF)-induced phosphorylation of c-MET, and subsequently inhibited HGF promotion of breast cancer cell migration in a c-MET-dependent manner [28] . MiR-335 expression was increased after 5-aza-2'-deoxycytidine (5-AZA-CdR) treatment, and 5-AZA-CdR treatment resulted in the same phenotype as the effect of miR-335 overexpression. MiR-34a inhibited cell growth and induced apoptosis partly by targeting MET in HGF-induced gefitinib-resistant HCC827 and PC-9 cells.

In summary, we have reported the first evidence that the SNPs rs76322625 and rs41281081 in the MET 3'UTR are involved in the occurrence of NSCLC by acting as a stimulating factor, and this may be one of the reasons for overexpression of MET in human NSCLC. The SNP rs41281081 can be regulated by miR-1026 and rs76322625 can be regulated by miR-335 to cause an up-regulation of MET in patients. These SNPs were also found to be related to the clinicopathological features of NSCLC, suggesting that they may have important roles in promoting tumor development. Our results support the hypothesis that genetic variants interrupting miRNA-mediated regulation and tumor suppressors are involved in the etiology of NSCLC.

\section{Disclosure Statement}

None declared.

\section{References}

1 Aggarwal C: Targeted therapy for lung cancer: present and future. Ann Palliat Med 2014;3:229-235.

2 Santarpia M, Altavilla G, Pitini V, Rosell R: Personalized treatment of early-stage non-small-cell lung cancer: the challenging role of EGFR inhibitors. Future Oncol 2015;11:1259-1274.

3 Van Der Steen N, Pauwels P, Gil-Bazo I, Castanon E, Raez L, Cappuzzo F, Rolfo C: cMET in NSCLC: Can We Cut off the Head of the Hydra? From the Pathway to the Resistance. Cancers (Basel) 2015;7:556-573.

4 Tian Z, Yao G, Song H, Zhou Y, Geng J: IGF2R expression is associated with the chemotherapy response and prognosis of patients with advanced NSCLC. Cell Physiol Biochem 2014;34:1578-1588.

5 Yun M, Kim EO, Lee D, Kim JH, Kim J, Lee H, Lee J, Kim SH: Melatonin sensitizes H1975 non-small-cell lung cancer cells harboring a T790M-targeted epidermal growth factor receptor mutation to the tyrosine kinase inhibitor gefitinib. Cell Physiol Biochem 2014;34:865-872.

6 Xia Y, Chen Q Zhong Z, Xu C, Wu C, Liu B, Chen Y: Down-regulation of miR-30c promotes the invasion of non-small cell lung cancer by targeting MTA1. Cell Physiol Biochem 2013;32:476-485.

7 Shi C, Qian J, Ma M, Zhang Y, Han B: Notch 3 protein, not its gene polymorphism, is associated with the chemotherapy response and prognosis of advanced NSCLC patients. Cell Physiol Biochem 2014;34:743752.

8 Harris FT, Rahman SM, Hassanein M, Qian J, Hoeksema MD, Chen H, Eisenberg R, Chaurand P, Caprioli RM, Shiota M, Massion PP: Acyl-coenzyme A-binding protein regulates Beta-oxidation required for growth and survival of non-small cell lung cancer. Cancer Prev Res (Phila) 2014;7:748-757. 


\section{Cellular Physiology Cell Physiol Biochem 2015;37:1159-1167 \begin{tabular}{l|l} 
and Biochemistry Published online: September 25, 2015 & $\begin{array}{l}\text { C) 2015 S. Karger AG, Basel } \\
\text { www.karger.com/cpb }\end{array}$ \\
\hline
\end{tabular} \\ Zhu et al.: MiRNA Associated SNPs in NSCLC}

9 Wu F, Zhang J, Liu Y, Zheng Y, Hu N: HIF1alpha genetic variants and protein expressions determine the response to platinum based chemotherapy and clinical outcome in patients with advanced NSCLC. Cell Physiol Biochem 2013;32:1566-1576.

10 Anagnostou VK, Brahmer JR: Cancer Immunotherapy: A Future Paradigm Shift in the Treatment of NonSmall Cell Lung Cancer. Clin Cancer Res 2015;21:976-984.

11 Antonicelli A, Cafarotti S, Indini A, Galli A, Russo A, Cesario A, Lococo FM, Russo P, Mainini AF, Bonifati LG, Nosotti M, Santambrogio L, Margaritora S, Granone PM, Dutly AE: EGFR-targeted therapy for non-small cell lung cancer: focus on EGFR oncogenic mutation. Int J Med Sci 2013;10:320-330.

12 Asami K, Atagi S: Epidermal growth factor receptor tyrosine kinase inhibitors for non-small cell lung cancer. World J Clin Oncol 2014;5:646-659.

13 Park S, Choi YL, Sung CO, An J, Seo J, Ahn MJ, Ahn JS, Park K, Shin YK, Erkin OC, Song K, Kim J, Shim YM, Han J: High MET copy number and MET overexpression: poor outcome in non-small cell lung cancer patients. Histol Histopathol 2012;27:197-207.

14 Garofalo M, Romano G, Di Leva G, Nuovo G, Jeon YJ, Ngankeu A, Sun J, Lovat F, Alder H, Condorelli G, Engelman JA, Ono M, Rho JK, Cascione L, Volinia S, Nephew KP, Croce CM: EGFR and MET receptor tyrosine kinase-altered microRNA expression induces tumorigenesis and gefitinib resistance in lung cancers. Nat Med 2012;18:74-82.

15 Reid JF, Sokolova V, Zoni E, Lampis A, Pizzamiglio S, Bertan C, Zanutto S, Perrone F, Camerini T, Gallino G, Verderio P, Leo E, Pilotti S, Gariboldi M, Pierotti MA: miRNA profiling in colorectal cancer highlights miR-1 involvement in MET-dependent proliferation. Mol Cancer Res 2012;10:504-515.

16 Watanabe K, Emoto N, Hamano E, Sunohara M, Kawakami M, Kage H, Kitano K, Nakajima J, Goto A, Fukayama M, Nagase T, Yatomi Y, Ohishi N, Takai D: Genome structure-based screening identified epigenetically silenced microRNA associated with invasiveness in non-small-cell lung cancer. Int J Cancer 2012;130:2580-2590.

17 Wang J, Yang B, Han L, Li X, Tao H, Zhang S, Hu Y: Demethylation of miR-9-3 and miR-193a genes suppresses proliferation and promotes apoptosis in non-small cell lung cancer cell lines. Cell Physiol Biochem 2013;32:1707-1719.

18 Plasterk RH: Micro RNAs in animal development. Cell 2006;124:877-881.

19 Wu N, Zhang C, Bai C, Han YP, Li Q: MiR-4782-3p inhibited non-small cell lung cancer growth via USP14. Cell Physiol Biochem 2014;33:457-467.

20 Zhang H, Zhao M, Lv Z, Zhang X, Qin X, Wang H, Wang S, Su J, Lv X, Liu H, Du W, Zhou W, Chen X, Fei K: MiR138 inhibits tumor growth through repression of EZH2 in non-small cell lung cancer. Cell Physiol Biochem 2013;31:56-65.

21 Valastyan S, Reinhardt F, Benaich N, Calogrias D, Szasz AM, Wang ZC, Brock JE, Richardson AL, Weinberg RA: A pleiotropically acting microRNA, miR-31, inhibits breast cancer metastasis. Cell 2009;137:10321046.

22 Hyun S, Lee JH, Jin H, Nam J, Namkoong B, Lee G, Chung J, Kim VN: Conserved MicroRNA miR-8/miR-200 and its target USH/FOG2 control growth by regulating PI3K. Cell 2009;139:1096-1108.

23 Bartel DP: MicroRNAs: genomics, biogenesis, mechanism, and function. Cell 2004;116:281-297.

24 Wang Y, Zhou L, Chen J, Li J, He L, Wu P, Wang M, Tong N, Zhang Z, Fang Y: Association of the 3'UTR FOXO3a polymorphism rs4946936 with an increased risk of childhood acute lymphoblastic leukemia in a Chinese population. Cell Physiol Biochem 2014;34:325-332.

25 Zhang L, Qian J, Qiang Y, Huang H, Wang C, Li D, Xu B: Down-regulation of miR-4500 promoted non-small cell lung cancer growth. Cell Physiol Biochem 2014;34:1166-1174.

26 Chen JT, Lin TS, Chow KC, Huang HH, Chiou SH, Chiang SF, Chen HC, Chuang TL, Lin TY, Chen CY: Cigarette smoking induces overexpression of hepatocyte growth factor in type II pneumocytes and lung cancer cells. Am J Respir Cell Mol Biol 2006;34:264-273.

27 Xu L, Nilsson MB, Saintigny P, Cascone T, Herynk MH, Du Z, Nikolinakos PG, Yang Y, Prudkin L, Liu D, Lee JJ, Johnson FM, Wong KK, Girard L, Gazdar AF, Minna JD, Kurie JM, Wistuba, II, Heymach JV: Epidermal growth factor receptor regulates MET levels and invasiveness through hypoxia-inducible factor-1alpha in nonsmall cell lung cancer cells. Oncogene 2010;29:2616-2627.

28 Gao Y, Zeng F, Wu JY, Li HY, Fan JJ, Mai L, Zhang J, Ma DM, Li Y, Song FZ: MiR-335 inhibits migration of breast cancer cells through targeting oncoprotein c-Met. Tumour Biol 2015;36:2875-2883. 